\title{
Maturation and quality of 'BRS Magna' grapes influenced by rootstocks in rainy season
}

\author{
Luana Ferreira dos Santos ${ }^{1}$, José Henrique Bernardino Nascimento ${ }^{2}$, Antônio Augusto Marques Rodrigues ${ }^{1(0)}$, Eugenio Ribeiro de \\ Andrade Neto ${ }^{3(0)}$, Maria Auxiliadora Coêlho de Lima ${ }^{*}$ (i)
}

\author{
'Universidade Federal da Paraíba/Centro de Ciências \\ Agrárias - Depto. de Fitotecnia, C.P. 66 - 58397-000 - \\ Areia, PB - Brasil. \\ ¿Universidade Federal do Recôncavo da Bahia/Centro \\ Ciências Agrárias, Ambientais e Biológicas - Depto. de \\ Fitotecnia, R. Rui Barbosa, 710 - 44380-000 - Cruz das \\ Almas, BA - Brasil. \\ 3Universidade de Pernambuco - Depto. de Ciências Exatas e \\ Naturais, BR 203 - 66328-900 - Petrolina, PE - Brasil. \\ ${ }^{4}$ Embrapa Semiárido, BR 428, km 152, C.P. 23 - 56302- \\ 970 - Petrolina, PE - Brasil. \\ *Corresponding author <auxiliadora.lima@embrapa.br>
}

Edited by: Lincoln Zotarelli

Received July 22, 2020

Accepted January 25, 2021
ABSTRACT: Seasonal variations and production factors can influence the quality of grapes. Considering the Sub-middle region of the São Francisco Valley, Brazil, differentiated by production in rainy and warmer periods of the year, the climatic conditions in each season affect the duration of the phenological phases and quality of the grapes. The objective of this study was to characterize the changes in the quality components during maturation of 'BRS Magna' grapes on different rootstocks, in rainy seasons under tropical conditions, as a support to define the harvest time. The experiment was conducted in Petrolina, Pernambuco, Brazil, from Jan to Apr 2017 (cycle 1) and Dec 2017 to Apr 2018 (cycle 2) evaluating rootstocks and age of the fruits. Bunches were picked from the start of maturation to the harvest: 49, 56, 61, 64 and 68 days after fruit set (DAF) for cycle 1 , and 35, 41, 48, 55, 61, and 66 DAF for cycle 2. In cycle 1 'IAC 572 ' and 'Paulsen 1103' rootstocks provided higher sugar contents in grapes, which was only repeated in cycle 2 for 'Paulsen 1103'. The accumulation of anthocyanins and yellow flavonoids was favored by 'IAC 313' and 'IAC 572' rootstocks in cycle 1, and by 'IAC 313' and 'IAC 766' in cycle 2. A higher content of polyphenols was conferred on 'IAC 572' in cycle 1 and on 'IAC 766' in cycle 2 , which also had a greater antioxidant capacity. Although there were differences between rootstocks, harvesting at approximately $64 \mathrm{DAF}$ maximized grape quality for all treatments.

Keywords: harvest time, hybrid grapes, juice grapes, tropical viticulture

\section{Introduction}

Vine cultivation is spread throughout various countries and climatic conditions, serving different markets. In addition to increasing consumption of fresh grapes, as observed in the last decade, there has been an increasing interest in grape products, especially juices (FAO, 2017). Grape production in the tropical zone of Brazil has increased considerably and the Sub-middle region of the São Francisco Valley, northwest of São Paulo State, and north of Minas Gerais State are the main producing centers. In these regions, the lowest temperatures are insufficient to induce dormancy; nevertheless, the use of technology allows for two or more annual harvests (Oliveira et al., 2018).

In the Sub-middle region of the São Francisco Valley, grape production is aimed mainly at fresh consumption. However, production of grapes for the juice industry has increased by the introduction of Brazilian cultivars, such as Isabel Precoce (Vitis labrusca) and hybrids 'BRS Violeta', 'BRS Cora' and 'BRS Magna' (Dutra et al., 2018b).

Since grapes can be produced in any period of the year, climatic conditions in each period can alter the synthesis of chemical compounds, which can add value to products from tropical regions when stimulated (Padilha et al., 2017; Dutra et al., 2018a). In these regions, temperature differences can affect duration of the cycles (Oliveira et al., 2018); however, the intensity of these variations has not yet been characterized.

Agronomic components are also determinants of fruit quality. For viticulture, rootstocks play an important role in commercial production in most producing areas worldwide. Rootstock vigor allows to control plant growth and improve grape quality, mitigating climate influence between cycles. Some studies have confirmed this response (Li et al., 2019; Silva et al., 2018; BascunánGodoy et al., 2017; Lo'ay and El-Khateeb, 2017). However, specificities for scion cultivars and cultivation regions require evaluations for each situation.

This study aimed to characterize changes in the quality components during maturation of 'BRS Magna' grapes grafted onto different rootstocks in rainy seasons under tropical conditions as a support to define the harvesting time.

\section{Materials and Methods}

\section{Study site}

The study was carried out during two productive cycles (2017/2018) in an experimental site at $09^{\circ} 08^{\prime} 03^{\prime \prime} \mathrm{S}$, $40^{\circ} 18^{\prime} 40^{\prime \prime} \mathrm{W}$, altitude $372 \mathrm{~m}$, in a Plinthic Eutrophic RedYellow Argisol with a medium/clayey texture and flat relief in Petrolina, Pernambuco, Brazil. According to the Köppen classification, the climate in this municipality is the BSh type, with very hot and dry periods of nine months and rainfall from Feb to Apr (Alvares et al., 2013).

Table 1 shows the meteorological data for the study period registered by an agrometeorological station situated at the experimental site.

\section{Cultivation conditions and production pruning}

The study was carried out in a BRS Magna cultivar ('BRS Rubea' X 'IAC 1398-21') vineyard planted in Aug 2014 
Table 1 - Monthly meteorological data during the two production cycles when maturation and quality of 'BRS Magna' grapes were studied from production pruning to harvest.

\begin{tabular}{|c|c|c|c|c|c|c|c|c|}
\hline \multirow{2}{*}{$\begin{array}{l}\text { Month/ } \\
\text { year }\end{array}$} & \multicolumn{3}{|c|}{$\mathrm{T}\left({ }^{\circ} \mathrm{C}\right)$} & \multirow{2}{*}{$\mathrm{RH}$} & \multirow{2}{*}{ Rad } & \multirow{2}{*}{ Ws } & \multirow{2}{*}{ Rainfall* $^{*}$} & \multirow[t]{2}{*}{ ETO } \\
\hline & Max. & Mean & Min. & & & & & \\
\hline & & & & $\%$ & $M J m^{-2} d^{-1}$ & $\mathrm{~m} \mathrm{~s}^{-1}$ & $\mathrm{~mm}$ & $\mathrm{~mm} \mathrm{~d}^{-1}$ \\
\hline & \multicolumn{8}{|c|}{ Jan to Apr 2017 (Production cycle 1) } \\
\hline Jan/17 & 36.0 & 29.3 & 23.4 & 45.1 & 18.2 & 2.4 & 10.0 & 6.3 \\
\hline Feb/17 & 35.8 & 29.1 & 23.4 & 54.0 & 19.8 & 2.0 & 24.0 & 5.8 \\
\hline Mar/17 & 34.2 & 28.8 & 22.6 & 57.6 & 19.8 & 1.8 & 6.0 & 5.5 \\
\hline Apr/17 & 32.7 & 28.0 & 21.9 & 62.0 & 17.4 & 2.4 & 3.0 & 5.4 \\
\hline \multirow[t]{2}{*}{ Mean } & 34.7 & 28.8 & 22.8 & 54.7 & 18.8 & 2.1 & 10.8 & 5.7 \\
\hline & \multicolumn{8}{|c|}{ Dec 2017 to Apr 2018 (Production cycle 2) } \\
\hline $\mathrm{Dec} / 17$ & 36.1 & 29.3 & 24.0 & 59.7 & 25.7 & 1.9 & 20.0 & 6.5 \\
\hline Jan/18 & 35.0 & 28.3 & 23.3 & 65.1 & 23.7 & 2.0 & 43.0 & 6.0 \\
\hline Feb/18 & 33.7 & 27.3 & 23.1 & 80.0 & 21.5 & 1.2 & 66.0 & 4.9 \\
\hline Mar/18 & 34.1 & 27.5 & 22.9 & 81.2 & 22.9 & 0.9 & 109.0 & 4.8 \\
\hline Apr/18 & 32.2 & 26.2 & 21.6 & 79.3 & 20.6 & 1.1 & 101.0 & 4.3 \\
\hline Mean & 34.2 & 25.6 & 25.0 & 73.0 & 22.8 & 1.4 & 67.8 & 5.3 \\
\hline
\end{tabular}

Mean $\mathrm{T} .=$ mean temperature; $\mathrm{T}$ Max. = maximum temperature; $\mathrm{T}$ Min. = minimum temperature; $\mathrm{RH}=$ relative humidity; $\mathrm{Rad}=$ global solar radiation; $\mathrm{Ws}=$ wind speed at $2.0 \mathrm{~m}$ height; Rainfall = accumulated rainfall; ETO = reference evapotranspiration. ${ }^{\star}$ Total monthly rainfall. Source: Agrometeorological Station of Bebedouro, Petrolina, Pernambuco, Brazil - Embrapa (2018).

with the plants trained to overhead trellis system, spaced at $4.0 \times 2.0 \mathrm{~m}$ and irrigated using microsprinklers. Two production cycles were studied: from 9 Jan to $17 \mathrm{Apr}$ 2017 and from 27 Dec 2017 to 2 Apr 2018. The first fruiting cycle started on 8 Feb 2017 and the second cycle on 27 Jan 2018.

\section{Treatments}

The treatments corresponded to rootstocks and age of fruits, characterizing the maturity stages. We evaluated six rootstocks among the most important adopted for grapevines for fresh consumption and for winemaking in the region: 'IAC 313 ' ('Golia' $\times$ Vitis smalliana), 'IAC 572 ' (Vitis caribaea $\times$ '101-14 Mgt'), 'IAC 766' ('106-8 Mgt' $\times$ Vitis caribaea), 'Paulsen 1103' (Vitis berlandieri $\times$ Vitis rupestris), 'Harmony' and 'Freedom', both having the same parents (Vitis champinii $\times$ Vitis vinifera $\times$ Vitis labrusca $\times$ Vitis riparia). Bunches were taken periodically from the start of grape maturation, recognized from the color change of berries and the start of softening. The collections were made 49,56,61, 64, and 68 days after fruit set (DAF) for the first cycle, and 35, 41, 48, 55, 61, and 66 DAF for the second cycle.

\section{Variables analyzed}

The bunches were analyzed for: bunch weight (BuW), berry weight (BeW), berry resistance to compression (COMP), titratable acidity (TA), soluble solids content (SS), total soluble sugars (TSS), total anthocyanins (ANT), yellow flavonoids (FLA), total extractable polyphenols (TEP), and the total antioxidant capacity (TAC).

Bunch weight (g) corresponded to the average weight of five recently picked bunches weighed using a semi-analytical balance. Berry weight (g) was determined by the average of 10 grapes from different regions of each bunch, weighed on a semi-analytical balance. Berry resistance to compression $(\mathrm{N})$ was determined in 20 grapes placed longitudinally in a digital texturometer equipped with a P/75 pressure plate, which allowed pressing to $20 \%$ of the volume using a pre-test velocity of $1.00 \mathrm{~mm} \mathrm{~s}^{-1}$, test velocity of $2.00 \mathrm{~mm} \mathrm{~s}^{-1}$, pressure of $5.0 \mathrm{~g}$, and distance of $5.00 \mathrm{~mm}$.

The SS content $(\%)$ was measured in the must (AOAC, 2010) using a portable digital refractometer with temperature compensation. The TSS contents /g 100 $\left.\mathrm{g}^{-1}\right)$ were quantified using the anthrone reagent and a spectrophotometer at $620 \mathrm{~nm}$ (Yemn and Willis, 1954). The TA ( $\mathrm{g}$ tartaric acid $100 \mathrm{~mL}^{-1}$ ) was determined by titrating with $0.1 \mathrm{~N} \mathrm{NaOH}$ to the neutral point (AOAC, 2010) using a digital automatic titrator.

The ANT and FLA contents (mg $100 \mathrm{~g}^{-1}$ ) were quantified in grape skins in an acidified alcoholic solution with readings at $535 \mathrm{~nm}$ and $374 \mathrm{~nm}$, respectively (Francis, 1982). The TEP contents (mg gallic acid $100 \mathrm{~g}^{-1}$ ) were quantified at $700 \mathrm{~nm}$ in the ground skin extracts and pulp macerated in $50 \%$ methanol and $70 \%$ acetone solutions using the Folin Ciocalteau reagent (Larrauri et al., 1997).

The TAC was determined in the same extracts used to quantify the TEP, using the free radical capture methods 2,2-diphenyl-1-picrylhydrazyl (DPPH $\bullet$ ) and 2,2'-azino-bis 3-ethylbenzene-thiazoline-6-sulfonic acid $\left(\mathrm{ABTS}^{\bullet}\right)$, aiming to obtain more information on the functional potential of the samples, since there are differences in the reactive mechanisms and sensitivities of the methods, for example. The ABTS radical method, expressed in $\mu \mathrm{M}$ Trolox $\mathrm{g}^{-1}$, followed the recommendations of Miller et al. (1993) with adaptations 
proposed by Rufino et al. (2010). Diluted aliquots of samples together with the $\mathrm{ABTS}^{\bullet+}$ radical were read at $734 \mathrm{~nm}$. The DPPH radical capture method (g grape $\mathrm{g}^{-1} \mathrm{DPPH}$ ) was used according to Sánchez-Moreno et al. (1998) with adaptations suggested by Rufino et al. (2010) with extracts of aliquots in a $0.06 \mathrm{mM}$ solution of DPPH and readings at $515 \mathrm{~nm}$.

\section{Experimental design and statistical analyses}

The experimental design was a randomized block with plots subdivided in time for each production cycle studied. The rootstocks were distributed among the plots and dates or ages of the grapes in the sub-plots. Four replicates were made with six plants in each, from which five bunches were picked for each collection. For cycle 1, 120 plots were studied ( 6 rootstocks $\times 5$ collection dates $\times 4$ blocks), while in cycle 2, 144 plots were studied $(6$ rootstocks $\times 6$ collection dates $\times 4$ blocks).

The data of each cycle that presented a normal distribution analyzed by the Shapiro-Wilk test were submitted separately to an analysis of variance. When significant, the data were submitted to a regression analysis using the program Statistical Analysis System, version 9.2. Polynomial equations up to the $3^{\text {rd }}$ degree were accepted, since most variables related to grape quality have their contents stabilized at the end of the maturation stage. This biological behavior can be better represented by the $3^{\text {rd }}$ degree polynomial equations than by the $2^{\text {nd }}$ degree. In addition, determination coefficients above $70 \%$ and significance of regression parameters according to the $t$ test are considered. The Tukey test was applied to compare rootstocks. The data that did not characterize a normal distribution were shown using means at the $95 \%$ of confidence level.

The Pearson's coefficient correlation was analyzed to infer the contributions of compounds associated to the functional potential on the total antioxidant capacity. The principal component analysis (PCA) was applied to all variables in order to recognize the ones that most differed between the rootstocks and identify the importance of each variable for each component. Two components were studied according to the criterion of the minimum number of components reaching at least $70 \%$ of the total variance.

\section{Results and Discussion}

In both cycles, bunch weight was influenced by the isolated effect of fruit age and rootstock (Figures 1A and $1 \mathrm{~B})$. In cycle 1 , first semester of 2017, there was a decrease during maturation. The use of 'Harmony' rootstock resulted in a lower bunch weight for the scion cultivar than for 'IAC 313', not differing from the others (Figure 1A). In cycle 2, first semester of 2018, bunch weight increased from the start of maturation to $61 \mathrm{DAF}$, followed by a slight drop until harvest. In turn, bunch weight of plants grafted onto 'IAC 572' was greater than in 'Freedom' and 'Harmony' (Figure 1B). Even with the shorter maturation period in cycle 1, after $61 \mathrm{DAF}$, bunches of the scion cultivar were characterized by a regular standard of weight between the cycles. In this phenological phase, increases in bunch weight and grape volume are due to greater translocation of water induced by an accumulation of solutes in the cells (Doumouya et al., 2014), as characterized in cycle 2 .

The interaction between the rootstock and fruit age only affected berry weight in cycle 1 (Figure 1C), in which rootstock 'IAC 313 ' provided a greater increase in weight of the scion cultivar grapes up to 61 DAF and berry weight tended to stabilize after this point. Grapes of plants grafted onto 'Freedom', 'Harmony' and 'Paulsen 1103' rootstocks weighed less at the end of maturation than in an intermediate phase. In cycle 2 , berries increased in weight throughout maturation (Figure 1D). The use of 'IAC 572' rootstock resulted in heavier grapes than in treatments grafting onto 'Freedom', 'Harmony' and 'Paulsen 1103'.

The increase in size and berry weight during maturation is related to the increase in cell volume, especially of the vacuoles (Borghezan, 2017), which is influenced by the genotype, number of seeds, the source-sink ratio, and the plant response to climatic conditions of each semester associated to accumulation of solutes and water (Borghezan, 2017; Doumouya et al., 2014). Regarding the effects of rootstocks on the quality components, Borges et al. (2014) observed no differences in the number of bunches per plant or of berries per bunch for cultivar Concord grafted onto 'IAC 766' and 'IAC 572'. Thus, specific responses for the scion cultivars grafted onto the same rootstock are highlighted.

A reduction in berry resistance to compression and subsequent stabilization is expected during maturation. However, the grapes from plants grafted onto 'IAC 313' showed an increase after 56 DAF as compared to the first evaluations, which could be associated with sampling variation (Figure 1E). After this period, the values decreased and tended to stabilize. The variation throughout the maturation period could be related to changes in translocation of water and nutrients to the grapes, determining their turgidity. When the whole period was considered, grapes from plants grafted onto the 'Freedom' rootstock were only more resistant to compression in the initial phase and practically stabilized after 64 DAF. For cycle 2, responses between the rootstocks were equivalent after 55 DAF with a tendency to stabilize afterward (Figure 1F). Few studies address the issue, particularly referring to plant management. Lo'ay and El-khateeb (2017) reported greater resistance for berries from 'Flame Seedless' vine grafted onto 'Paulsen 1103', a moderate vigor rootstock.

The different responses in both cycles could be attributed to the duration of maturation. In cycle 2, maturation was identified in the initial phase and started relatively slower, highlighting the loss of compression 

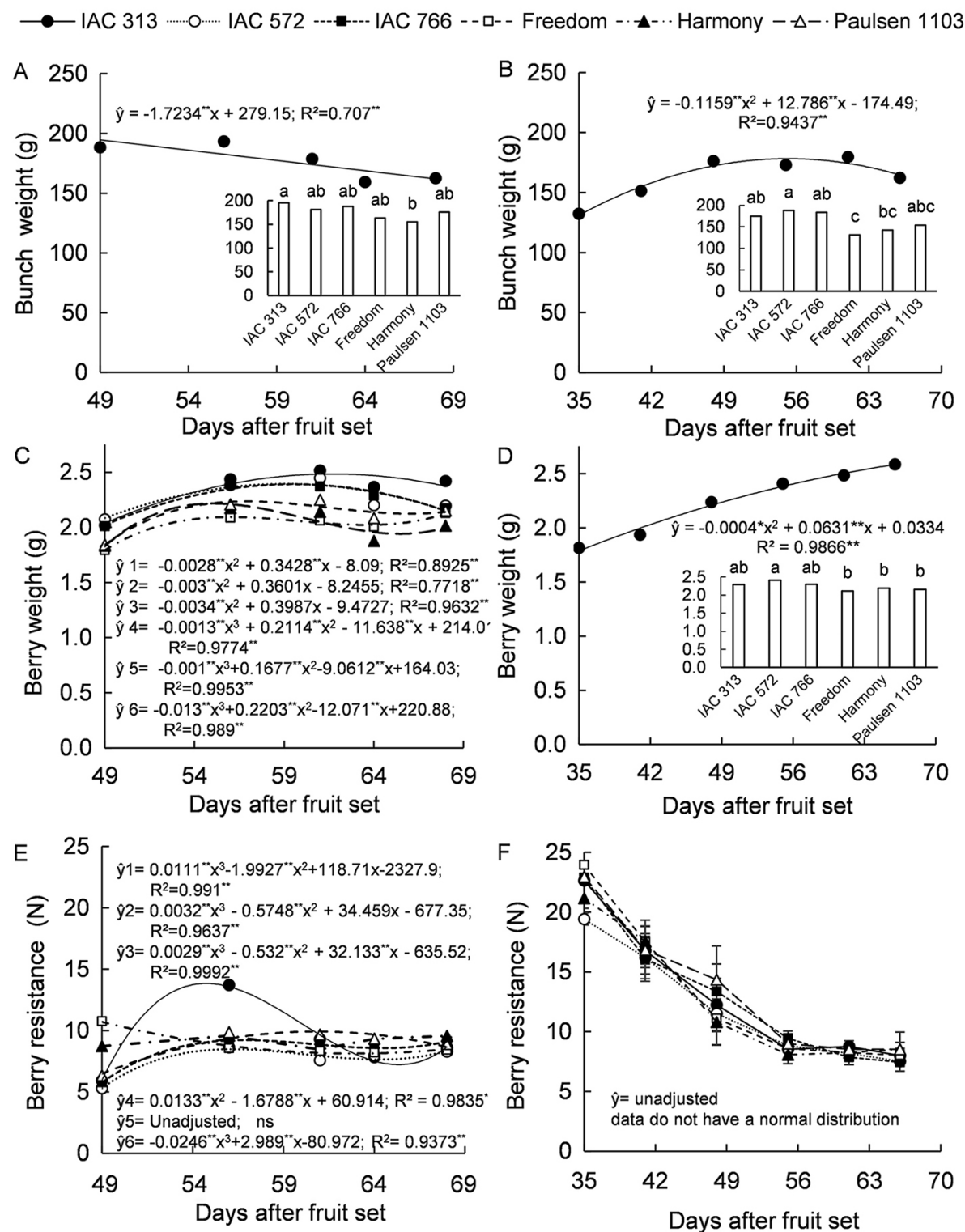

Figure 1 - Bunch weight ( $A$ and $B$ ), berry weight ( $C$ and $D$ ), and berry resistance to compression ( $E$ and $F$ ) during the maturation of grapes from 'BRS Magna' vines cultivated by grafting onto different rootstocks and evaluated from Jan to Apr 2017 (to the left) and from Dec 2017 to Apr 2018 (to the right) cycles. Means followed by the same letter in the graphs with internal bars in Figures 1A, 1B, and 1D, evaluating the isolated effect of the rootstocks, did not differ from one another according to the Tukey test $(p<0.05)$. ${ }^{*},{ }^{*}$ Statistical significance by the t test at $p$ $<0.05$ and $p<0.01$, respectively. Vertical bars in Figure $1 \mathrm{~F}$ represent the confidence interval at $95 \%$ confidence level. Rootstocks: IAC 313 (ŷ1); IAC 572 (ŷ2); IAC 766 (ŷ3); Freedom (ŷ4); Harmony (ŷ5); Paulsen 1103 (ŷ6).

resistance. In cycle 1 , response of stabilization of the loss of compression resistance of grapes was already observed at the start of the sampling of grapes. For grapes allocated for juice production, a reduced compression resistance of berries facilitates separation of the peduncle. This effect may be due to enzymatic degradation of cell wall in this part of the grape (Lo'ay, 2011), resulting in greater yield during the destemming phase, which favors the grape maceration phase. In addition, skin components, such as pigments, may be easier to extract from grapes showing less resistance to compression (Coletta et al., 2018).

There was significant interaction in both cycles between fruit age and rootstock on soluble solids contents (SS) and the total soluble sugar contents (TSS), ratifying the progressive increase during maturation (Figures 2A, 2B, 2C, and 2D). For cycle 1, the SS contents in the first sampling were higher than for cycle 2 (Figures 2A and 2B), when the response of rootstocks on the scion grapes was more uniform, reaching $21.2 \%$ 
in vines grafted onto 'Freedom' rootstock (Figure 2B). In cycle 1, fruits from plants grafted onto 'IAC 572' were highlighted for their SS content of $23.2 \%$, higher than that reported by Ritschel et al. (2015) for this cultivar, followed by the treatments with 'IAC 766' and 'Paulsen 1103'. Grapes from plants grafted onto 'IAC 313' showed a slower increase in the SS content.

In a study evaluating rootstocks for Syrah grapevines grown under autumn-winter season through double pruning management, Dias et al. (2017) observed improvement in grape and wine quality when high vigor rootstocks were adopted. Wooldridge et al. (2016) reported that grapes from a 'Pinot Noir' vine grafted onto ' $110 \mathrm{R}^{\prime}$ produced better wine than when grafted onto 'Richter 99', 'Ruggeri 140', or 'SO4'. For grape cultivars for juice production produced in Brazil, such as Isabel Precoce, BRS Carmem, Bordo, BRS Violeta and Concord Clone 30, Mota et al. (2018) reported values for SS lower than those observed in our study for vines grafted onto 'Paulsen 1103' in tropical conditions. The values reported by Silva et al. (2018) for 'BRS Cora', 'Isabel Precoce', and 'BRS Carmem' grafted on 'IAC 572' or 'IAC 766', were also lower than those found for 'BRS Magna' in our study.

The SS content is an indirect measurement of the sugar content and depends on factors, such as the cultivar, grape size, plant yield, and climatic conditions. It can also suffer variations due to water loss, which concentrates the solutes, or an increase in water absorption after rain or excess of irrigation (Kuhn et al., 2014). The period of cycle 2 was characterized by greater precipitation (Table 1), which may have increased grape volume and diluted the solutes (sugars, acids, tannins, anthocyanins, and others).

The response for the TSS content followed the same tendency for the SS content, highlighting the values found for grape vines grafted onto 'Paulsen 1103' in cycle

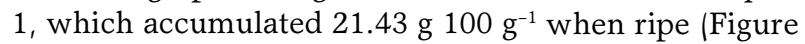
2C). Differently from the other rootstocks, 'IAC 572' promoted greater TSS and SS contents in scion grapes after 56 DAF. However, the use of this rootstock resulted

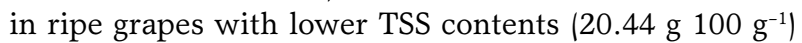
than with 'Paulsen 1103'. In cycle 2, the use of rootstock 'Freedom' favored grapes with higher TSS contents,

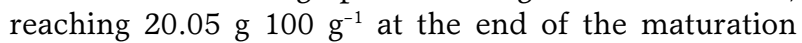
period (Figure 2D). The response for this rootstock in this cycle is consistent with the high SS contents (Figure 2B). These values were higher than those reported by Ritschel et al. (2015) of 17 and 19 'Brix for 'BRS Magna' grapes in tropical and temperate climates.

The sugar content maintains a relationship with accumulated solar radiation and high temperatures (Kuhn et al., 2014) and greater accumulation of SS and TSS under these conditions must be due to stimulation of the photosynthetic rates (Gatti et al., 2014). Concerning the cycles, in addition to higher mean temperatures, the low relative humidity and reduced rainfall in cycle 1 possibly favored a higher sugar concentration. Air temperature influences transpiration and thus regulates the hydric needs of the vine. The higher the temperature, the lower the relative humidity and the greater the water loss by transpiration, resulting in concentration of SS (Tarara et al., 2008).

In cycle 1 , the common reduction in titratable acidity (TA) tending to stabilize at the end of maturation was observed with slight significant differences between the rootstocks: $0.08 \mathrm{~g}$ tartaric acid $100 \mathrm{~mL}^{-1}$ at $68 \mathrm{DAF}$ (Figure 2E). Ritschel et al. (2015) mentioned that mean TA of cultivar BRS Magna grafted on 'Paulsen 1103' or 'IAC 572 ' was $0.90 \mathrm{~g}$ tartaric acid $100 \mathrm{~mL}^{-1}$ in a temperate climate region. Silva et al. (2018) mentioned a mean value of $0.87 \mathrm{~g}$ tartaric acid $100 \mathrm{~mL}^{-1}$ for 'Isabel Precoce', 'BRS Carmem' and 'IAC 138-22 Máximo' grapes under tropical conditions. These values are higher than those observed for 'BRS Magna' grapes in our study in the Brazilian semiarid tropical region.

Observations of both cycles suggest a lower TA for grapes of cycle 1 (Figures $2 \mathrm{E}$ and $2 \mathrm{~F}$ ), when temperatures were higher during the maturation (Table 1). Temperature has a strong influence on the organic acid contents, since degradation is accelerated under high temperatures (Kuhn et al., 2014). The ripening process also accelerates degradation and increases membrane permeability. These phenomena allow sugars and organic acids stored in vacuoles to be consumed by respiration (Kliewer et al., 1967).

Tartaric and malic acids account for about $90 \%$ of the organic acids in the cell vacuoles of grapes. The decrease on the contents of both acids during maturation is mainly explained by the dilution of tartaric acid, while malate is intensely used in respiration (Borghezan, 2017).

In addition to quantifying organic acids and sugars as quality indicators, the phenolic composition should also be considered in grapes. An effect of the interaction between rootstock and fruit age was verified for the yellow flavonoid contents in cycle 1 , but not in cycle 2 , when data did not have a normal distribution (Figures $3 \mathrm{~A}$ and 3B). In cycle 1 after $64 \mathrm{DAF}$, rootstocks 'Harmony', 'Freedom' and 'IAC 572' promoted greater accumulation of these pigments in scion grapes (Figure 3A). However, treatment 'IAC 572 ' resulted in the highest value at the end of maturation. Variations in the contents of different flavonoids can be attributed to genetic factors, climate, vine handling, grape maturity state, and grape size (Rockenbach et al., 2011), as well as the extraction and evaluation methods of these compounds.

In our study, the contents of yellow flavonoid decreased with the proximity of harvest. The higher yellow flavonoid contents in cycle 2 (Figure 3B) can be justified by the greater global solar radiation (Table 1). Impacts of solar light and temperature on grape composition on the synthesis of these compounds have been studied. For example, grape temperature can influence the activity of enzymes flavonoid- $3^{\prime}, 5^{\prime}$ hydroxylase and flavonoid-3'hydroxylase, inducing changes in accumulation (Angelotti-Mendonça et al., 
2018). The use of 'IAC 313', a very high vigor rootstock, favored the accumulation of yellow flavonoids in the 'BRS Magna' grapes at harvest compared to 'IAC 572' and 'Harmony', which are considered moderate vigor rootstocks (Figure $3 \mathrm{~B}$ ).

There was an interaction between rootstocks and fruit age for the anthocyanin content in grape skins only for cycle 1 (Figure 3C). The content increased during maturation up to $64 \mathrm{DAF}$, when it reached its maximum value, such as yellow flavonoids, and then decreased. Some authors reported that exposure of vines to solar radiation or to temperatures below $25^{\circ} \mathrm{C}$ stimulated the synthesis and accumulation of anthocyanins in grapes. On the other hand, temperatures above $35{ }^{\circ} \mathrm{C}$ have been associated to anthocyanin degradation (Hickey and Woolf, 2018; Tarara et al., 2008). A decrease in the contents of these pigments may also be associated to a decrease in synthesis (Fernández-López et al., 1998). At the end of maturation in cycle 1, the highest anthocyanin contents were found for vines grafted onto the most vigorous rootstocks evaluated, 'IAC 313' and 'Freedom' (Figure 3C).

In cycle 2, the anthocyanin contents increased with all rootstocks, despite lower values at the start of
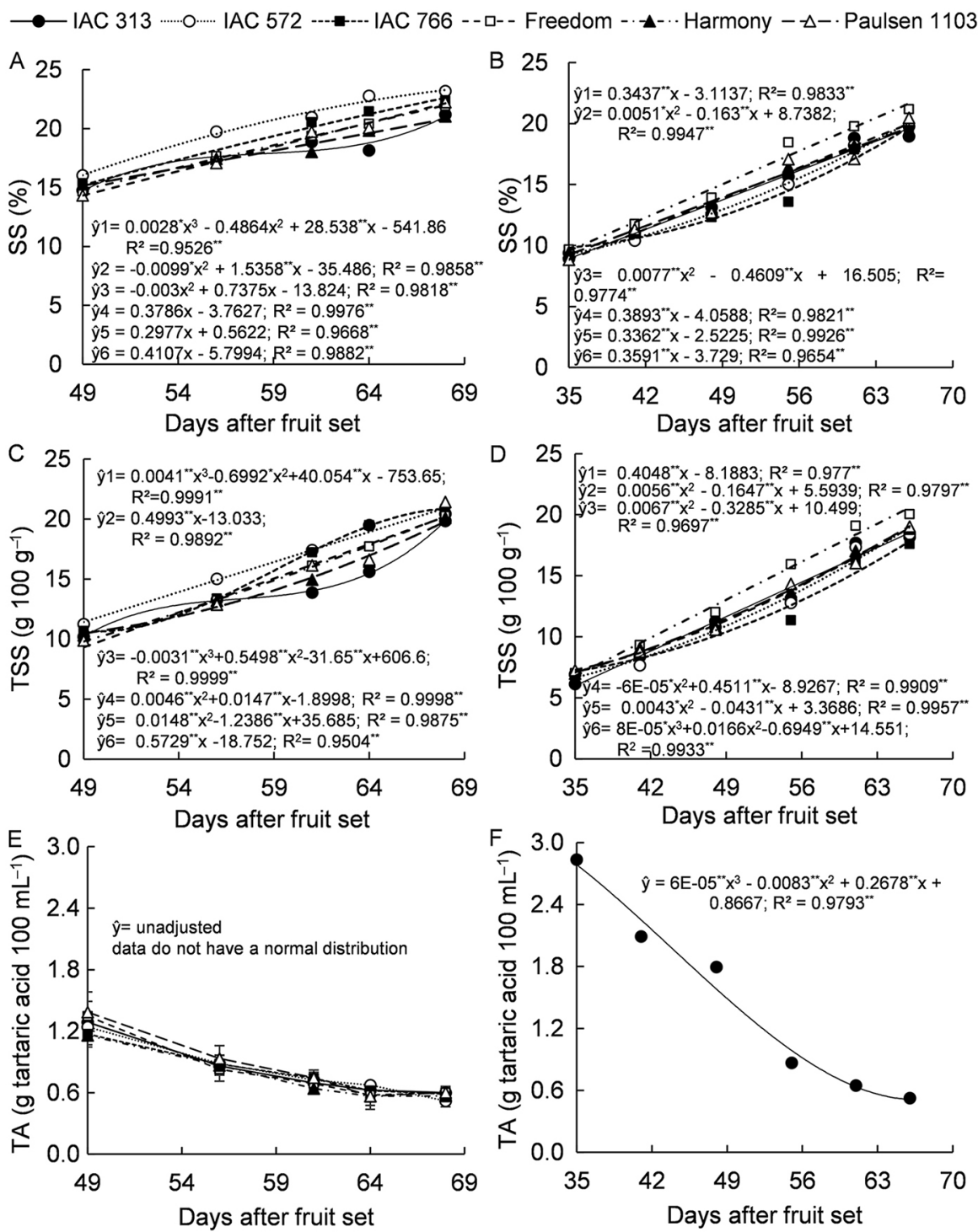

Figure 2 - Soluble solids ( $A$ and $B$ ) content, total soluble sugars ( $C$ and D), and titratable acidity ( $E$ and F) during the maturation of grapes from 'BRS Magna' vines cultivated by grafting onto different rootstocks and evaluated from Jan to Apr 2017 (to the left) and Dec 2017 to Apr 2018 (to the right) cycles; ${ }^{*},{ }^{*}$ Statistical significance by the t test at $p<0.05$ and $p<0.01$, respectively. Vertical bars in Figure $2 \mathrm{E}$ represent the confidence interval at $95 \%$ confidence level. In Figure $2 F$, it is evaluated the isolated effect of the age of fruits (days after fruit set). Rootstocks: IAC 313 (ŷ1); IAC 572 (ŷ2); IAC 766 (ŷ3); Freedom (ŷ4); Harmony (ŷ5); Paulsen 1103 (ŷ6). 
maturation, when grapes started to change color. In this cycle, the highest contents were found mainly in grapes from plants grafted onto 'IAC 313' and 'IAC 766', reaching values of $673.16 \mathrm{mg}, 100 \mathrm{~g}^{-1}$ and $708.02 \mathrm{mg}$, $100 \mathrm{~g}^{-1}$, respectively at harvest. Silva et al. (2017) studied cultivars Cabernet Sauvignon, Cabernet Franc, and IAC 138-22 Máximo and reported higher anthocyanin contents for grapes of vines grafted onto 'IAC 766 '. The authors also observed that grapes of 'BRS Violeta' accumulated more anthocyanins when vines were grafted onto '106-8 Mgt'. Another study found no differences in quality attributes for 'Concord' grapes grafted onto rootstocks 'IAC 766' and 'IAC 572' (Borges et al., 2014). In addition to the distinct responses between scion cultivars and climate influence, vigor intensity conferred by different rootstocks to scion cultivars may be fundamental for changes in physicochemical attributes of grapes (Bascunán-Godoy et al., 2017). However, the physiological and/or biochemical interactions between scion grapes and rootstocks associated to these effects are still an object of study.

Both cycles showed a differential accumulation on TEP as a function of the rootstock (Figures 3E and $3 \mathrm{~F})$. For cycle 1 , the highest contents were observed
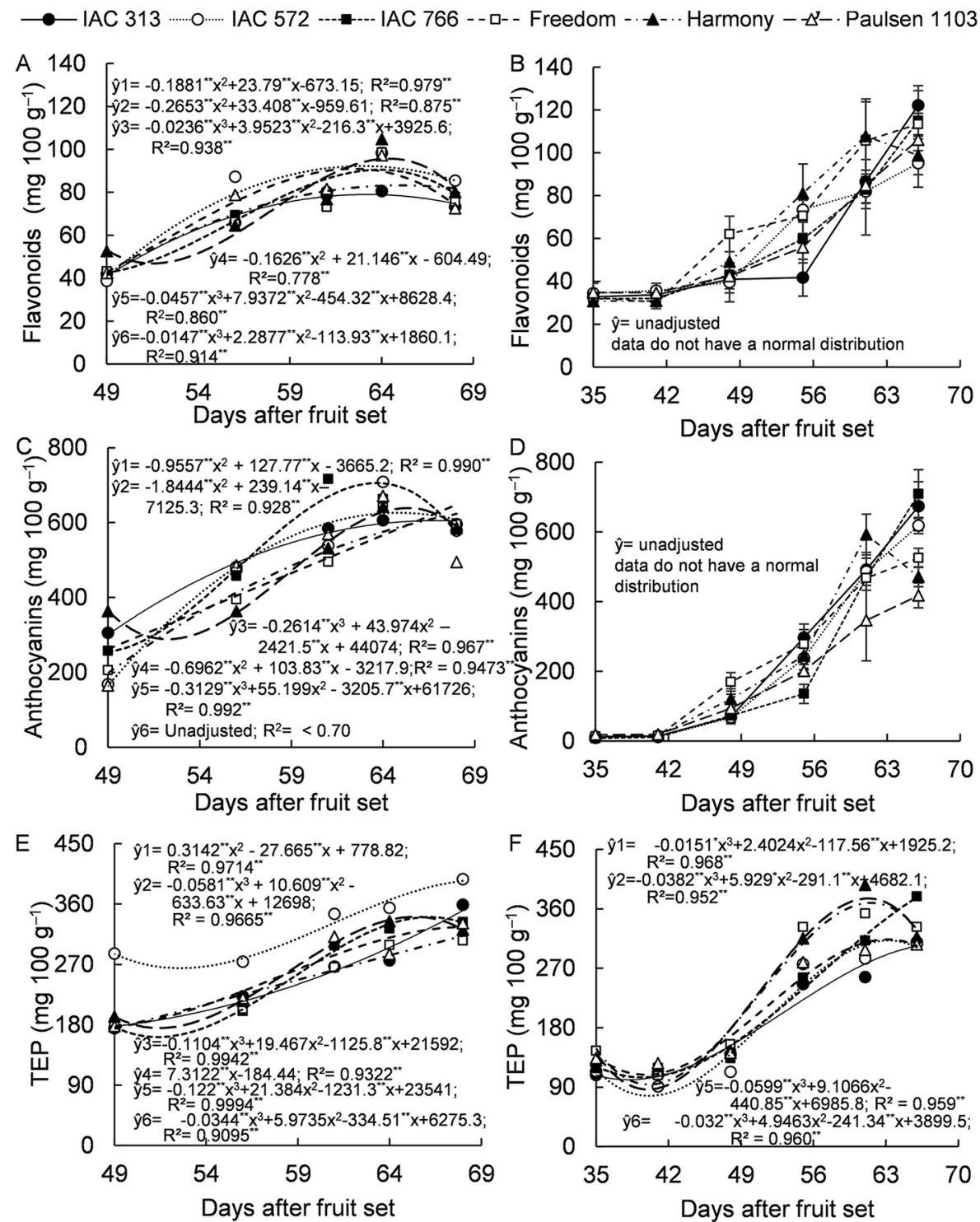

Figure 3 - Contents of yellow flavonoids ( $A$ and $B$ ) and total anthocyanins in grape skins ( $C$ and $D$ ) and total extractable polyphenols - TEP (E and F) during maturation of grapes from 'BRS Magna' vines cultivated by grafting onto different rootstocks and evaluated from Jan to Apr 2017 (to the left) and from Dec 2017 to Apr 2018 (to the right) cycles; ${ }^{*},{ }^{*}{ }^{*}$ Statistical significance by the test at $p<0.05$ and $p<0.01$, respectively.

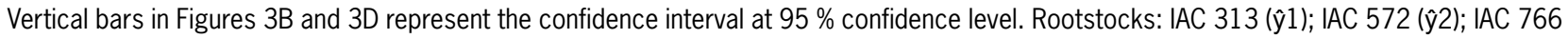

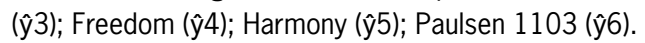


for grapes from vines grafted onto 'IAC 572' and 'IAC 313': 397.12 and $358.84 \mathrm{mg} 100 \mathrm{~g}^{-1}$, respectively, after 68 DAF. This is coherent with the high yellow flavonoid content associated to 'IAC 572' in cycle 1 at harvest time and represents an important part of the total polyphenol compound contents. In general, the differences promoted by rootstocks on the polyphenol compound contents of grapes are related to vigor, water and nutrient absorption capacity, and disease resistance, as well as their interaction with scion, affecting the metabolites of plants and consequently the productive capacity and quality of grapes (Tecchio et al., 2014). In cycle 2, the highest TEP contents were observed at the end of the maturation period in grapes from plants grafted onto 'IAC 766' (Figure 3F). This response could be related to vigor levels conferred by the rootstocks 'IAC 572', known to be more vigorous than 'IAC 766'. When grafted onto rootstocks that induce less vigor, grapes have a higher phenolic compound content (Silva et al., 2017). Conversely, higher yielding and vigorous rootstocks possibly induce sufficient phenolic composition for a good quality of the product, as reported by Dias et al. (2017) in 'Syrah' grapevine.

Habran et al. (2016) discussed interactions between soil composition, rootstocks, and scion as selective parameter for a variety, a rootstock, a compound, and a berry compartment, which also depend on climate. The authors highlighted that a rootstock can favor a higher amount of phenolics, as anthocyanins, hydroxycinnamic acids, stilbenes, and flavan-3-ols. However, the effect can vary even within the same group of chemical compounds.

Distinct responses were also observed during maturation between rootstocks for TAC, as determined by the $\mathrm{DPPH}^{\circ}$ method (Figures $4 \mathrm{~A}$ and $4 \mathrm{~B}$ ). In cycle 1 , differences between rootstocks could have been related to fruit age (Figure 4A) with values decreasing from 56 to $61 \mathrm{DAF}$ and then stabilizing. Using this method, lower values represent more TAC since they indicate that less fruit mass needs to be consumed to correspond to the radical activity (Floegel et al., 2011). In cycle 2, TAC increased up to 61 DAF and the values decreased afterward in grapes from plants grafted onto all rootstocks. The distinct responses for different cycles corroborated observations of $\mathrm{Xu}$ et al. (2011) in that, in subtropical areas, climate conditions affect the accumulation of phenolic compounds in vine cultivars, leading to differences in TAC in grapes.

Using the $\mathrm{ABTS}^{\bullet}+$ free radical capture method, TAC also increased for all rootstocks and all fruit ages
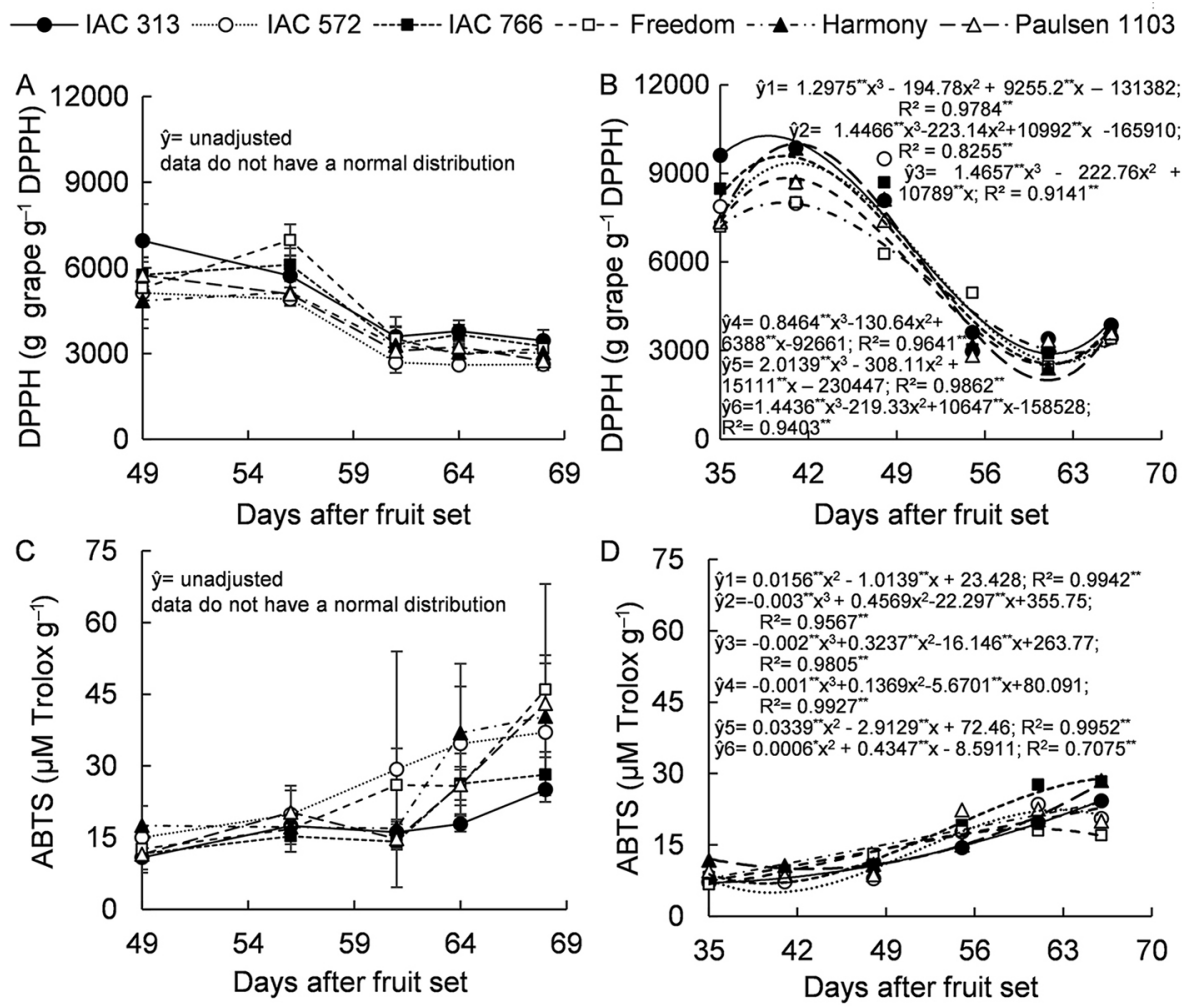

Figure 4 - Total antioxidant capacity measured by 2,2-diphenyl-1-picrylhydrazyl - DPPH• (A and B) and 2,2'-azino-bis; 3-ethylbenzene-thiazoline-6sulfonic acid - ABTS •+ (C and D) free radical capture methods during maturation of grapes from 'BRS Magna' vines cultivated by grafting onto different rootstocks and evaluated from Jan to Apr 2017 (to the left) and from Dec 2017 to Apr 2018 (to the right) cycles; *, * * Statistical significance by the t test at $p<0.05$ and $p<0.01$, respectively. Vertical bars in Figures $4 \mathrm{~A}$ and $4 \mathrm{C}$ represent the confidence interval at $95 \%$

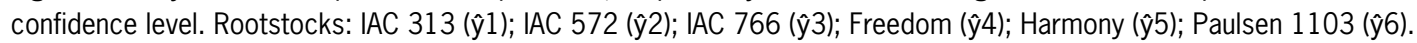


in both cycles (Figures 4C and 4D). In cycle 1, grapes from plants grafted onto 'Harmony' and 'Paulsen 1103' showed a great variation in TAC during maturation, presenting the highest values at harvest. In cycle 2 , the highest TAC values were observed in grapes from plants grafted onto 'IAC 766' and 'Harmony' at the end of maturation. The evaluation of TAC by the ABTS method corroborated the responses observed using DPPH for the treatment with rootstock 'Paulsen 1103'.

The values obtained for TAC by the ABTS and DPPH methods are correlated to each other, indicating that one method can extract equivalent conclusions from one or the other techniques, even under the influence of rootstocks (Figures 5A and 5B). The highest correlation coefficients were observed between the yellow flavonoid contents and the anthocyanin contents for both cycles. Separately, these variables presented correlation coefficients close to $70 \%$ for TEP in cycle 1 and $85 \%$ in cycle 2 . In general, the TEP content was the variable that best correlated with the methods used to determine TAC. Contributions of yellow flavonoids and anthocyanins to the TEP content were also verified, with correlation coefficients especially high in cycle 2 .

The PCA showed that $85.6 \%$ of data variability was explained by the two principal components (Figure 6). The first component (PC1) highlighted the data representativeness for all the variables, except bunch weight, also showed the differences due to rootstocks and maturity stages/fruit ages for both cycles. Among the variables, only TA, COMP, and DPPH presented negative auto-vectors. PC1 separated the treatments corresponding to more advanced maturity stages from the initial one (M1), particularly for cycle 1 . The auto-values for PC1 suggested that grapes with higher contents of TSS, anthocyanins, yellow flavonoids, TEP, and TAC, evaluated by the ABTS method, were associated to maturity stages after 60 DAF. In addition, rootstocks 'Freedom' and 'Paulsen 1103' promoted greater SS and TSS contents to grapes, while the use of 'IAC 313' and 'Freedom' resulted in grapes with high contents of anthocyanins. In turn, rootstocks 'Freedom' and 'Harmony' were associated to the highest value for TAC by the ABTS ${ }^{\bullet+}$ method, while the initial maturity stages were characterized by the lowest value for TAC by the DPPH $\bullet$ method.

PC2 distinguished the rootstock treatments in particular, the most representative data were obtained for bunch and berry weights, for which the auto-vectors were positive (Figure 6). For both cycles, treatments 'IAC 313', 'IAC 572', and 'IAC 766' were separated from the others in PC2. The variable TA was efficient in separating grapes harvested in each cycle and grapes from the second cycle were characterized by lower values.

Even rootstocks that did not promote the greatest accumulation of compounds or mass values or even high berry resistance to compression in 'BRS Magna' grapes showed adequate quality for juice production. Thus, increments in grapes derived from some rootstocks represent opportunities for differentiation in the market.
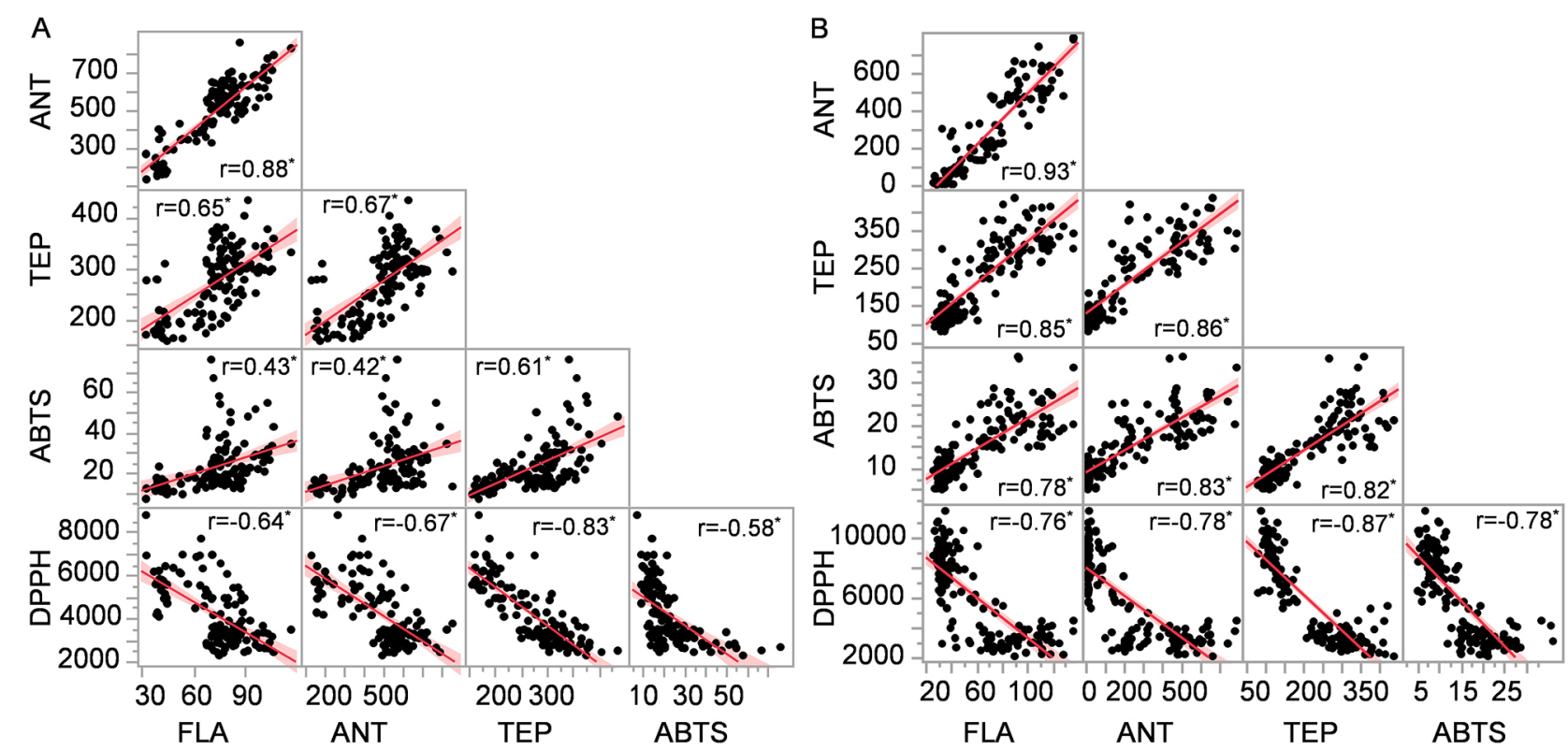

Figure 5 - Pearson's coefficients of correlation of bioactive compounds yellow flavonoids in skin (FLA), total anthocyanins in skin (ANT), total extractable polyphenols (TEP), and the total antioxidant capacity determined by 2,2'-azino-bis; 3-ethylbenzene-thiazoline-6-sulfonic acid (ABTS $\bullet+$ ) and 2,2-diphenyl-1-picrylhydrazyl (DPPH•) free radical capture methods during maturation of grapes from 'BRS Magna' vines cultivated by grafting onto different rootstocks and evaluated from Jan to Apr 2017 (A) and from Dec 2017 to Apr 2018 (B) cycles; *Significant at $p<0.05$. 


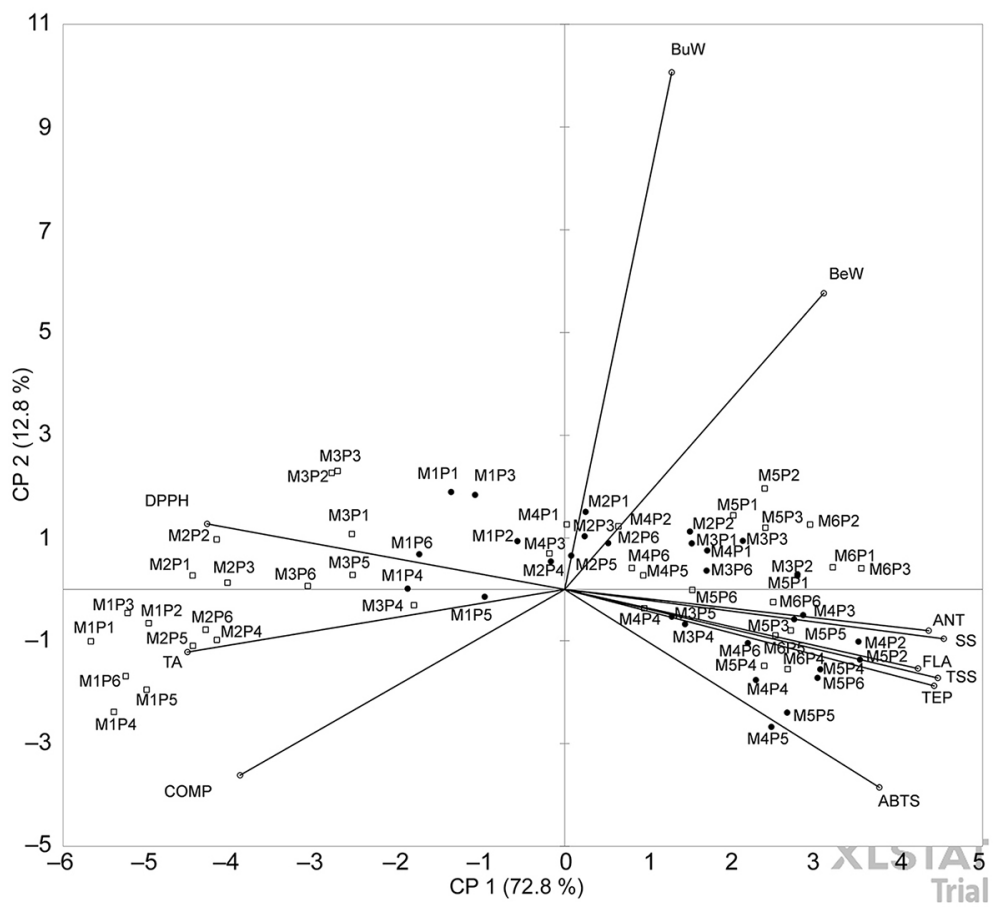

Figure 6 - Dispersion of variables based on auto-vectors of quality characteristics and the antioxidant capacity during ripening of grapes on the 'BRS Magna' vines cultivated after grafting onto different rootstocks and evaluated from Jan to Apr 2017 (cycle 1, •) and from Dec 2017 to Apr 2018 (cycle 2, 口) cycles. Treatments: M1 = maturity stage 1 corresponding to 49 days after fruiting (DAF) in the $1^{\text {st }}$ productive cycle (C1), and $35 \mathrm{DAF}$ in the $2^{\text {nd }}$ productive cycle (C2); M2 = maturity stage 2 corresponding to $56 \mathrm{DAF}$ in $\mathrm{C} 1$ and $41 \mathrm{DAF}$ in $\mathrm{C} 2$; M3 = maturity stage 3 corresponding to $61 \mathrm{DAF}$ in $\mathrm{C} 1$ and $48 \mathrm{DAF}$ in $\mathrm{C} 2$; M4 = maturity stage 4 , corresponding to $64 \mathrm{DAF}$ in $\mathrm{C} 1$ and $55 \mathrm{DAF}$ in $\mathrm{C} 2 ; \mathrm{M} 5=$ maturity stage 5 corresponding to $68 \mathrm{DAF}$ in $\mathrm{C} 1$ and $61 \mathrm{DAF}$ in $\mathrm{C} 2$; M6 = maturity stage 6 corresponding to 66 DAF; P1 = rootstock 'IAC 313'; P2 = rootstock 'IAC 572'; P3 = rootstock 'IAC 766'; P4 = rootstock 'Freedom'; P5 = rootstock 'Harmony'; P6 = rootstock 'Paulsen 1103'. Variables: BuW = bunch weight; BeW = berry weight; $\mathrm{SS}=$ soluble solids; $\mathrm{TSS}=$ soluble sugars content; $\mathrm{TA}=$ titratable acidity; COMP = berry resistance to compression; FLAV = yellow flavonoids in skin; ANT = total anthocyanins in skin; TEP = total extractable polyphenols; $\mathrm{ABTS}=$ antioxidant capacity by 2,2'-azino-bis; 3-ethylbenzene-thiazoline-6-sulfonic acid (ABTS ${ }^{\bullet+}$ ) method; DPPH = antioxidant capacity by 2,2-diphenyl1-picrylhydrazyl (DPPH•) method.

\section{Conclusions}

In the cycle characterized by low relative humidity and rainfall, rootstock 'IAC 313' favored bunch weight, berry weight, and total anthocyanins content of the 'BRS Magna' grapes, whereas 'IAC 572' promoted higher soluble solids, yellow flavonoids, and total extractable polyphenols contents, as well as lower acidity.

Rootstocks 'IAC 572', 'Paulsen 1103', and 'Freedom' favored the basic quality characteristics, such as sugars and titratable acidity, in addition to the functional potential due to the phenolic composition and antioxidant capacity. Increases in pigments, polyphenol compounds, and antioxidant capacity were pronounced in grafting onto 'IAC $766^{\prime}$, configuring an advantage for the use of this raw material. However, there were significant differences between the cycles associated to the use of this rootstock.

In rainy seasons, the greatest quality potential of the 'BRS Magna' grapes occurred approximately 64 DAF, considered adequate harvesting time, regardless of the rootstock.

\section{Authors' Contributions}

Conceptualization: Lima, M.A.C. Data acquisition: Santos, L.F.; Nascimento, J.H.B.; Rodrigues, A.A.M.; Andrade Neto, E.R.A. Data analysis: Santos, L.F.; Lima, M.A.C. Design of methodology: Lima, M.A.C. Writing and editing: Santos, L.F.; Lima, M.A.C.

\section{References}

Alvares, C.A.; Stape, J.L.; Sentelhas, P.C.; Gonçalves, J.L.M.; Sparovek, G. 2013. Köppen's climate classification map for Brazil. Meteorologische Zeitschrift 22: 711-728.

Angelotti-Mendonça, J.; Moura, M.F.; Scarpare Filho, J.A.; Vedoato, B.T.F.; Tecchio M.A. 2018. Rootstock on production and quality of 'Niagara Rosada' grapevine. Revista Brasileira de Fruticultura 40: 1-9.

Association of Official Agricultural Chemists [AOAC]. 2010. Official Methods of Analysis of the Association of the Agricultural Chemists. 18ed. AOAC, Gaithersburg, MD, USA. 
Bascunán-Godoy, L.; Franck, N.; Zamorano, D.; Sanhueza, C.; Carvajal, D.E.; Ibacache, A. 2017. Rootstock effect on irrigated grapevine yield under arid climate conditions are explained by changes in traits related to light absorption of the scion. Scientia Horticulturae 218: 284-292.

Borges, R.S.; Roberto, S.R.; Yamashita, F.; Assis, A.M.; Yamamoto, L.Y. 2014. Production and quality of 'Concord' clones of grapevine fruits on different rootstocks. Pesquisa Agropecuária Tropical 44: 198-204 (in Portuguese, with abstract in English).

Borghezan, M. 2017. Formation and ripening of grape and effects on the wines: review. Ciência e Técnica Vitivinícola 32: 126-141 (in Portuguese, with abstract in English).

Coletta, C.; Botondi, R.; Forniti, R.; Baccelloni, S.; Bellincontro, A.; Mencarelli, F. 2018. Alternating temperature in postharvest cooling treatment of 'Fiano' and 'Falanghina' grapes affects cell wall enzyme rate, berry softening, and polyphenols. Journal of the Science of Food and Agriculture 99: 3142-3148.

Dias, F.A.N.; Mota, R.V.; Souza, C.R.; Pimentel, R.M.A.; Souza, L.C.; Souza, A.L.; Regina, M.A. 2017. Rootstock on vine performance and wine quality of 'Syrah' under double pruning management. Scientia Agricola 74: 134-141.

Doumouya, S.; Lahaye, M.; Maury, C.; Siret, R. 2014. Physical and physiological heterogeneity within the grape bunch: impact on mechanical properties during maturation. American Journal of Enology and Viticulture 65: 170-178.

Dutra, M.C.P.; Souza, J.F.; Viana, A.C.; Oliveira, D.; Pereira, G.E.; Lima, M.S. 2018a. Rapid determination of the aromatic compounds methyl-anthranilate, 2'-aminoacetophenone and furaneol by GC-MS: method validation and characterization of grape derivatives. Food Research International 107: 613-618.

Dutra, M.C.P.; Rodrigues, L.L.; Oliveira, D.; Pereira, G.E.; Lima, M.S. 2018b. Integrated analyses of phenolic compounds and minerals of Brazilian organic and conventional grape juices and wines: validation of a method for determination of $\mathrm{Cu}, \mathrm{Fe}$ and Mn. Food Chemistry 269: 157-165.

Empresa Brasileira de Pesquisa Agropecuária [Embrapa]. 2018. Annual averages of the Agrometeorological Station of Bebedouro = Médias anuais da Estação Agrometeorológica de Bebedouro. Available at: http://www.cpatsa.embrapa.br:8080/servicos/ dadosmet/ceb-anual.html [Accessed Jan 3, 2019] (in Portuguese).

Fernández-López, J.A.; Almela, L.; Muñoz, J.A.; Hidalgo, V.; Carreño, J. 1998. Dependence between colour and individual anthocyanin content in ripening grapes. Food Research International 31: 667-672.

Floegel, A.; Kim, D.O.; Chung, S.J.; Koo, S.I.; Chun, O.K. 2011. Comparison of ABTS/DPPH assays to measure antioxidant capacity in popular antioxidant-rich US foods. Journal of Food Composition and Analysis 24: 1043-1048.

Food and Agriculture Organization [FAO]. 2017. Table and Dried Grapes: World Data Available. FAO-OIV, Rome, Italy.

Francis, F.J. 1982. Analysis of anthocyanins. p. 181-207. In: Markakis, P., ed. Anthocyanins as food colors. Academic Press, New York, NY, USA.

Gatti, M.; Garavani, A.; Cantatore, A.; Parisi, M.G.; Bobeica, N.; Merli, M.C.; Vercesi, A.; Poni, S. 2014. Interactions of summer pruning techniques and vine performance in the white Vitis vinifera cv. Ortrugo. Australian Journal of Grape and Wine Research 21: 80-89.
Habran, A.; Commisso, M.; Helwi, P.; Hilbert, G.; Negri, S.; Ollat, N.; Gomès, E.; van Leeuwen, C.; Guzzo, F.; Delrot, S. 2016. Roostocks/scion/nitrogen interactions affect secondary metabolism in the grape berry. Frontiers of Plant Science 7: 1134.

Hickey, C.C.; Wolf, T.K. 2018. Leaf removal effects on Cabernet franc and Petit Verdot. I. Crop yield components and primary fruit composition. American Journal of Enology and Viticulture 69: 221-230.

Kliewer, W.M.; Howarth, L.; Omori, M. 1967. Concentrations of tartaric acid and malic acids and their salts in Vitis vinifera grapes. American Journal of Enology and Viticulture 18: 42-54.

Kuhn, N.; Guan, L.; Dai, Z.; Wu, B.; Lauvergeat, V.; Gomès, E.; Li, S.; Godoy, F.; Arce-Johnson, P.; Delrot, S. 2014. Berry ripening: recently heard through the grapevine. Journal of Experimental Botany 65: 4543-4559.

Larrauri, J.A.; Rupérez, P.; Saura-Calixto, F. 1997. Effect of drying temperature on the stabilitity of polyphenols and antioxidant activity of red grape pomace peels. Journal of Agriculture and Food Chemistry 5: 1390-1393.

Li, M.; Guo, Z.; Jia, N.; Yuan, J.; Han, B.; Yin, Y.; Zhao, S. 2019. Evaluation of eight rootstocks on the growth and berry quality of 'Marselan' grapevines. Scientia Horticulturae 248: 58-61.

Lo'ay, A.A.; El-Khateeb, A.Y. 2017. Evaluation the effect of rootstocks on postharvest berries quality of 'Flame Seedless' grapes. Scientia Horticulturae 220: 299-302.

Lo'ay, A.A. 2011. Biological indicators to minimize berry shatter during handling of Thompson seedless grapevines. World Applied Sciences Journal 12: 1107-1113.

Miller, N.J.; Diplock, A.T.; Rice-Evans, C.; Davies, M.; Gopinathan, V.; Milner, A. 1993. A novel method for measuring antioxidant capacity and its application to monitoring the antioxidant status in premature neonates. Clinical Science 84: 407-412.

Mota, R.V.D.; Glória, M.B.A.; Souza, B.S.D.; Peregrino, I.; Pimentel, R.M.D.A.; Dias, F.A.N.; Regina, M.D.A. 2018. Bioactive compounds and juice quality from selected grape cultivars. Bragantia 77: 62-73.

Oliveira, J.B.; Faria, D.L.; Duarte, D.F.; Egipto, R.; Laureano, O.; Castro, R.; Ricardo-da-Silva, J.M. 2018. Effect of the harvest season on phenolic composition and oenological parameters of grapes and wines cv. 'Touriga Nacional' (Vitis vinifera L.) produced under tropical semi-arid climate, in the state of Pernambuco, Brazil. Ciência e Técnica Vitivinícola 33: 145166.

Padilha, C.V.S.; Miskinis, G.A.; Souza, M.E.A.O.; Pereira, G.E.; Oliveira, D.; Bordignon-Luiz, M.T.; Lima, M.D.S. 2017. Rapid determination of flavonoids and phenolic acids in grape juices and wines by RP-HPLC/ DAD: method validation and characterization of commercial products of the new Brazilian varieties of grape. Food Chemistry 228: 106-115.

Ritschel, P.S.; Girardi, C.L.; Zanus, M.C.; Fajardo, T.V.M.; Maia, J.D.G.; Souza, R.T.; Camargo, U.A. 2015. Novel Brazilian grape cultivars. Acta Horticulturae 1082: 157-163.

Rockenbach, I.I.; Gonzaga, L.V.; Rizelio, V.M.; Gonçalves, A.E.S.S.; Genovese, M.I.; Fett, R. 2011. Phenolic compounds and antioxidant activity of seed and skin extracts of red grape (Vitis vinifera and Vitis labrusca) pomace from Brazilian winemaking. Food Research International 44: 897-901. 
Rufino, M.M.; Alves, R.E.; Brito, E.S.; Pérez-Jiménez, J.; SauraCalixto, F.; Mancini-Filho, J. 2010. Bioactive compounds and antioxidant capacities of 18 non-traditional tropical fruits from Brazil. Food Chemistry 121: 996-1002.

Sánchez-Moreno, C.; Larrauri, J.A.; Saura-Calixto, F. 1998. A procedure to measure the antiradical efficiency of polyphenols. Journal of the Science of Food and Agriculture 76: 270-276.

Silva, M.J.R.; Paiva, A.P.M.; Pimentel Junior, A.; Sánchez, C.A.P.C.; Callili, D.; Moura, M.F.; Leonel, S.; Tecchio, M.A. 2018. Yield performance of new juice grape varieties grafted onto different rootstocks under tropical conditions. Scientia Horticulturae 241: 194-200.

Silva, M.J.R.; Vedoato, B.T.I.F.; Lima, G.P.P.; Moura, M.F.; Coser, G.M.D.A.G.; Watanabe, C.Y.; Tecchio, M.A. 2017. Phenolic compounds and antioxidant activity of red and white grapes on different rootstocks. African Journal of Biotechnology 16: 664-671.

Tarara, J.M.; Lee, J.; Spayd, S.E.; Scagel, C.F. 2008. Berry temperature and solar radiation alter acylation, proportion, and concentration of anthocyanin in Merlot grapes. American Journal of Enology and Viticulture 59: 235-247.
Tecchio, M.A.; Moura, M.F.; Teixeira, L.A.J.; Pires, E.J.P.; Leonel, S. 2014. Influence of rootstocks and pruning times on yield and on nutrient content and extraction in Niagara Rosada grapevine. Pesquisa Agropecuária Brasileira 49: 340-348.

Wooldridge, J.; Louw, P.J.E.; Conradie, W.J. 2016. Effects of rootstock on grapevine performance, petiole and must composition, and overall wine score of Vitis vinifera cv. Chardonnay and Pinot Noir. South African Journal of Enology and Viticulture 31: 45-48.

Yemn, E.W.; Willis, A.J. 1954. The estimation of carbohydrate in plant extracts by anthrone. The Biochemical Journal 57: 504514.

Xu, C.; Zhang, Y.; Zhu, L.; Huang, Y.; Lu, J. 2011. Influence of growing season on phenolic compounds and antioxidant properties of grape berries from vines grown in subtropical climate. Journal of Agricultural and Food Chemistry 59: 10781086 . 